\title{
ES2010-90402
}

\section{THERMAL MODELLING AND SIMULATION OF PARABOLIC TROUGH RECEIVER TUBES}

\author{
Markus Eck \\ German Aerospace Center (DLR) \\ 70569 Stuttgart, Germany
}

\author{
Jan Fabian Feldhoff \\ German Aerospace Center (DLR) \\ 70569 Stuttgart, Germany
}

\author{
Ralf Uhlig \\ German Aerospace Center (DLR) \\ 70569 Stuttgart, Germany
}

\begin{abstract}
Receiver tubes (or heat collecting elements - HCE) are a key component of parabolic trough solar thermal power plants. They are mounted in the focal line of the collectors, absorb the concentrated solar irradiance and transfer the absorbed energy to the heat transfer fluid flowing through them. During the design phase of the receiver tubes and for the performance prediction of solar thermal power plants it is helpful to derive their technical properties, like the thermal losses or the temperature field in the receiver tubes, from their physical and geometrical properties. For this purpose, several models have been developed in the past [1-3].

In this paper, the different existing models are presented, compared and assessed. It is found that a simple analytical model is a helpful tool for the fast prediction of the temperature distribution in the receiver tube. Furthermore, a 2-dimensional and a 3-dimensioanl model are compared regarding the heat losses of a HCE at different operation conditions. Both tools show a good agreement with available measurements. Finally with these tools the efficiency factor $F^{\prime}$ is calculated that considers the heat losses of an irradiated receiver compared to that of an un-irradiated receiver. According to the performed calculations, the efficiency factor of parabolic trough receivers is higher than expected.
\end{abstract}

Keywords: receiver tubes, thermal modeling, thermal losses

\section{NOMENCLATURE}

\section{Symbols}

$\begin{array}{ll}c_{p} & \text { specific heat capacity } \\ D_{0} & \text { outer diameter } \\ D_{i} & \text { inner diameter }\end{array}$

$[\mathrm{kJ} / \mathrm{kgK}]$

$[\mathrm{m}]$

$\begin{array}{llr}F^{\prime} & \text { efficiency factor } & {[-]} \\ G_{b} & \text { beam irradiance } & {\left[\mathrm{W} / \mathrm{m}^{2}\right]} \\ h_{f, I} & \text { heat transfer coefficient inside tube } & {\left[\mathrm{W} / \mathrm{m}^{2} \mathrm{~K}\right]} \\ k & \text { thermal conductivity } & {[\mathrm{W} / \mathrm{mK}]} \\ l & \text { length } & {[\mathrm{m}]} \\ \dot{m} & \text { mass flow } & {[\mathrm{kg} / \mathrm{s}]} \\ P_{\text {abs }} & \text { power absorbed by collector } & {[\mathrm{W}]} \\ P_{\text {coll }} & \text { thermal collector power } & {[\mathrm{W}]} \\ P_{\text {th.loss }} & \text { thermal losses of collector } & {[\mathrm{W}]} \\ Q_{a b s} & \text { power absorbed by HCE } & {[\mathrm{W}]} \\ q_{\text {loss,irr }} & \text { specific heat losses of irradiated receiver } & {[\mathrm{W} / \mathrm{m}]} \\ q_{\text {lossun,irr }} & \text { specific heat losses of un-irradiated receiver } & {[\mathrm{W} / \mathrm{m}]} \\ T_{a m b} & \text { ambient temperature } & {\left[{ }^{\circ} \mathrm{C}\right]} \\ T_{f, \text { out }} & \text { outlet temperature of fluid } & {\left[{ }^{\circ} \mathrm{C}\right]} \\ T_{f, \text { in }} & \text { inlet temperature of fluid } & {\left[{ }^{\circ} \mathrm{C}\right]} \\ \Delta T & \text { temperature difference } & {[\mathrm{K}]} \\ U_{L} & \text { collector overall heat loss coefficient } & {\left[\mathrm{W} / \mathrm{m}^{2} \mathrm{~K}\right]} \\ U_{0} & \text { overall heat transfer coefficient } & {\left[\mathrm{W} / \mathrm{m}^{2} \mathrm{~K}\right]}\end{array}$

\section{Abbreviations}

DNI Direct Normal Irradiance

DSG Direct Steam Generation

FEM Finite Element Method

HCE Heat Collecting Element

HTF Heat transfer fluid, here only synthetic oil

PTR State-of-the-art receiver tube coating of SCHOTT for temperatures up to $400^{\circ} \mathrm{C}$

SEGS Solar Energy Generating Systems, California

\section{INTRODUCTION}

A heat collecting element (HCE) is a key component of a parabolic trough collector field. The schematic diagram of a HCE is displayed in Figure 1. The heat transfer fluid (HTF) 
flowing through the steel receiver tube is usually a synthetic oil. This steel tube is covered with a selective coating. The selective coating has a high absorptivity in the visible range and a low emissivity in the infrared region. Thus the solar gain is optimized and at the same time the radiation losses are reduced to a minimum.

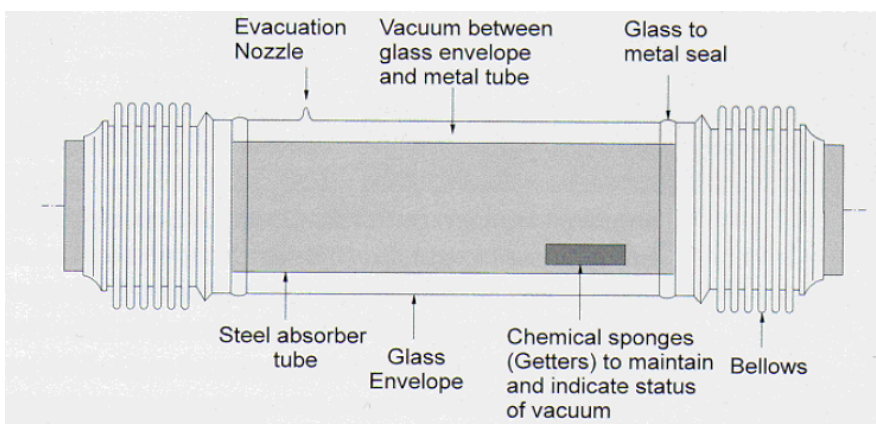

Figure 1: Schematic diagram of a heat collecting element.

To reduce the convective losses the receiver tube is surrounded by a glass envelope and the space between the steel and the glass tube is evacuated. The glass envelope is connected to the receiver tube by bellows. These bellows guarantee the vacuum tightness of the assembly and compensate the different thermal expansion of the steel and the glass tubes. To maintain the vacuum, getters are placed between the glass and the receiver tube to absorb gases that diffuse into the space.

Since the optical properties of the HCE determines the amount of solar irradiance absorbed by the HCE and the thermal properties determine the heat finally absorbed by the fluid, the performance characteristic of a parabolic trough collector field is mainly determined by the HCE characteristic.

In this paper, different simulation tools calculating the thermal performance of parabolic trough receivers are assessed. The programs are used to calculate the heat losses of the receiver at different operation conditions in order to estimate the efficiency factor of parabolic trough receivers.

\section{THEORETICAL BACKGROUND}

Usually the total energy yield of a parabolic trough collector field is determined as the absorbed power, reduced by prevailing thermal losses [4]:

$$
P_{\text {coll }}=P_{a b s}-P_{t h, l o s s}=\dot{m} \cdot c_{p}\left(T_{f, \text { out }}-T_{f, \text { in }}\right)
$$

Often the thermal losses of the HCE are measured in labscale tests. In this case a heat source brings the receiver tube to an elevated temperature above ambient. Ideally, the whole HCE has the same constant temperature. Under steady-state conditions, the power required to maintain the system at the constant temperature is equivalent to the thermal losses. Such tests are performed by electrically heating the receiver tube with constant, known electric power [4]. For the latter performance calculation of the collector fields, it is assumed that the receiver temperature measured in the tests is equivalent to the HTF temperature in a collector field.

This approach does not consider that the thermal losses of a HCE are determined by its outer surface temperature. When a $\mathrm{HCE}$ is heated electrically from the inside, the highest receiver temperature occurs at the inner surface of the receiver tubes. In reality, when the receiver tubes are irradiated at the outer surface, the highest temperature occurs at the outer surface. Accordingly the heat losses determined by these lab-scale tests are systematically lower than in reality.

This problem is well known. In [5], the efficiency factor $F^{\prime}$ is defined, as the ratio of the actual useful energy gain to the useful gain that would result if the collector absorbing surface had been at the local fluid temperature.

$$
F^{\prime}=\frac{1 / U_{L}}{\frac{1}{U_{L}}+\frac{D_{o}}{h_{f, i} D_{i}}+\frac{D_{o}}{2 k} \ln \frac{D_{o}}{D_{i}}}=\frac{U_{0}}{U_{L}}
$$

In this approach it is assumed that the solar irradiance is evenly distributed over the outer surface of the receiver tube and thus the receiver temperature at the outer surface is constant. In reality, the flux distribution on the outer surface of the receiver tubes is not uniform but has a distinct profile (cf. Figure 2). In consequence, the receiver temperature is also not constant, and the simplified approach of Equation 2 is no longer valid.

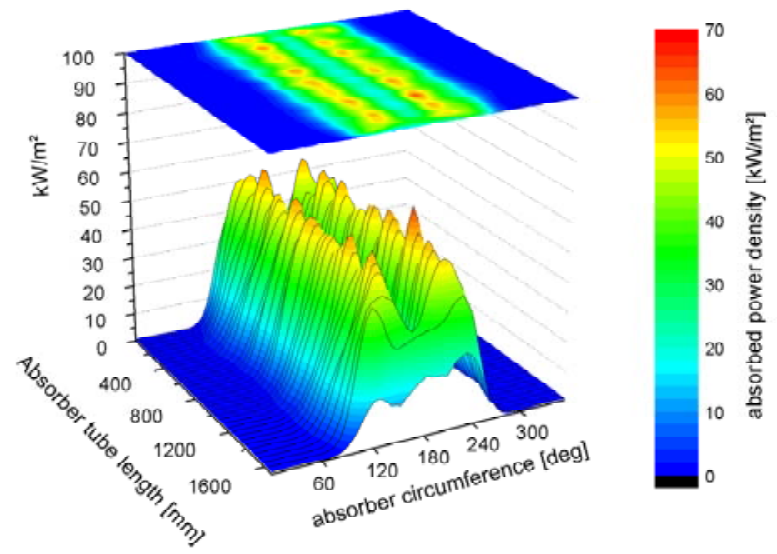

Figure 2: Typical irradiation profile on the outer surface of a parabolic trough HCE [6].

The effect of the non-uniform flux distribution on the real heat fluxes of a HCE has not been investigated in detail so far. This paper presents the first step towards the determination of an efficiency factor $F^{\prime}$ considering the effect of a flux distribution. For this purpose a detailed three-dimensional FEM model of a HCE is developed that considers the non-uniform flux distribution at the outer surface and the heat transfer at the inner surface.

In the next sections, the FEM model is presented and compared against other receiver models known from literature. 
Afterwards, the thermal losses of an irradiated and unirradiated HCE are calculated with the FEM tool and the Sandia model and the efficiency factor $F^{\prime}$ is calculated and compared to the efficiency factor according to Equation 2 for a specific load case.

\section{RECEIVER MODELS}

In this section three different HCE models are presented. Special attention is paid to the specific abilities of each model.

\subsection{Analytical Model}

An analytical model for the fast calculation of the temperature distribution on the mean perimeter an irradiated receiver tube has been developed by DLR and presented in [2]. Originally, this model was developed for the evaporation section of collectors for the direct steam generation (DSG). But it can be used in a modified version for every single phase HTF too.

The main assumption of the model is that in principle the inner boundary of the receiver tube can be wetted or un-wetted and the outer surface can be irradiated or un-irradiated (s. Figure 3). Accordingly, the cross-section can be sub-divided in four different segments
1. Wetted and heated
3. Un-wetted and unheated
2. Un-wetted and heated
4. Wetted and unheated

In case of a single phase HTF, only two different sections can be identified (irradiated and un-irradiated), which are particular cases of the common case.

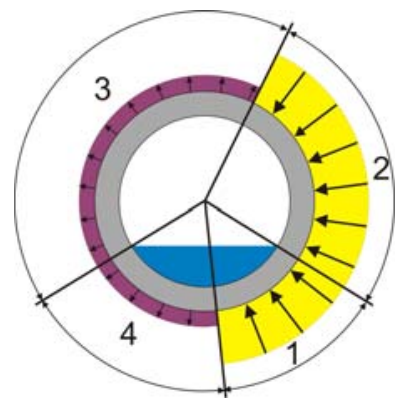

Figure 3: $\quad$ Schematic illustration of an receiver cross section with the four different sections.

The boundary conditions of the model are the heat transfer coefficient and the fluid temperature at the inner surface of the receiver tube as well as the heat flux at the outer surface of each segment. The heat losses are not considered directly, but only by a reduced heat flux at the outer surface. The assumptions named and the according boundary conditions lead to a linear set of equations that can be solved analytically. The final result is an equation for the calculation of the temperature distribution on the mean perimeter of the receiver tube. Since the heat losses are included in the boundary conditions a priory, they are not part of the results. The simple model can be implemented in every mathematical program such as MATLABC).

\subsection{Sandia Model}

A thermal model was developed to solve stationary, 1dimensional heat balances for a cross sectional area of an receiver tube by Sandia [1]. It uses a thermal node network as shown in Figure 4. It is assumed that the heat transfer can be described from the fluid (1) to the ambient (6) by the connection of different nodes by thermal resistances. Each node represents a temperature of a certain surface in radial direction and is connected to the next node by one or more parallel heat transfer mechanisms. E.g. the heat transfer between fluid (1) and inner receiver surface (2) is mainly based on convection.

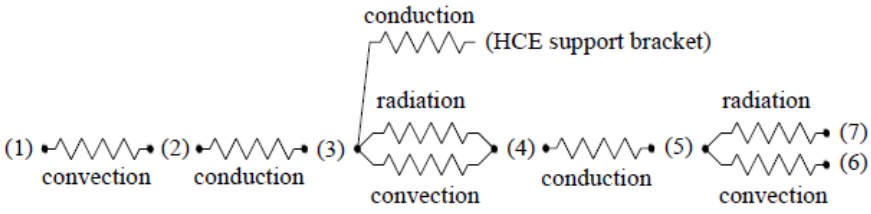

$\begin{array}{ll}\text { (1) heat transfer fluid } & \text { (5) glass envelope outer surface } \\ \text { (2) absorber inner surface } & \text { (6) surrounding air } \\ \text { (3) absorber outer surface } & \text { (7) sky } \\ \text { (4) glass envelope inner surface } & \end{array}$

Figure 4: Thermal network of Sandia's resistance model; Source: [7].

This model was implemented with the software Engineering Equation Solver and described in more detail by Forristall [7]. DLR implemented the model with the software Modelica/Dymola with the heat fluxes shown in Figure 5.

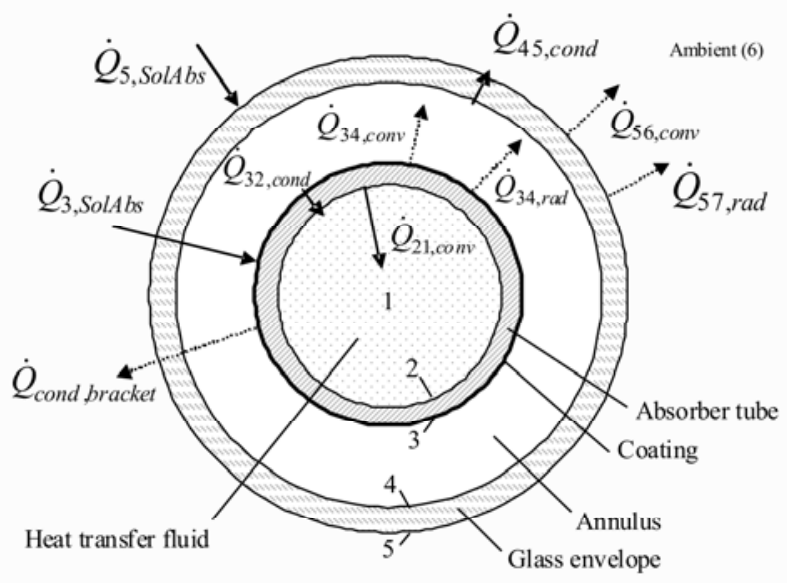

Figure 5: Heat fluxes of the 1-dimensional receiver tube model in radial direction.

The main solar input is $Q_{3, \text { SolAbs. }}$. For the heat loss calculation, also the direct solar input on the glass surface $Q_{5, \text { SolAbs }}$ has a significant influence. For the results presented in this paper, the heat loss of the receiver tube support brackets $Q_{\text {cond,bracket }}$ is neglected. All other heat fluxes are described by a suiting temperature-depending model and by applying energy 
conservation the resulting temperatures are calculated implicitly.

Due to the node model the radiation is distributed evenly over the whole circumference. In consequence, each surface has a constant temperature over the circumference. This assumption holds for un-irradiated heat loss conditions. The circumferential temperature distribution especially during irradiated conditions cannot be modelled with this simplified approach.

\subsection{Finite Element Method (FEM) Model}

To consider the local temperature distribution for the analysis of the thermal losses, a three-dimensional FEMModel was developed using the commercial FEM-code ANSYS. (The model was built using the parametric scripting language of the FEM code). The geometry was meshed using quadratic hexahedron elements with Temperature Degree of freedom. In circumferential direction the model is discretisized with 36 elements. Along the tube length 100 elements and over the wall thickness 1 element was used. The net independence was ensured by a mesh study.

The Model considers the receiver tube and the glass envelope (s. Figure 6). The absorbed solar radiation was considered using the two dimensional heat flux profile derived from raytracing simulations from Figure 2. The absorption of solar radiation in the glass envelope was considered with heat generation in the glass volume. The spatial distribution of the absorbed heat was derived from the two-dimensional flux profile used for the receiver tube heat fluxes.

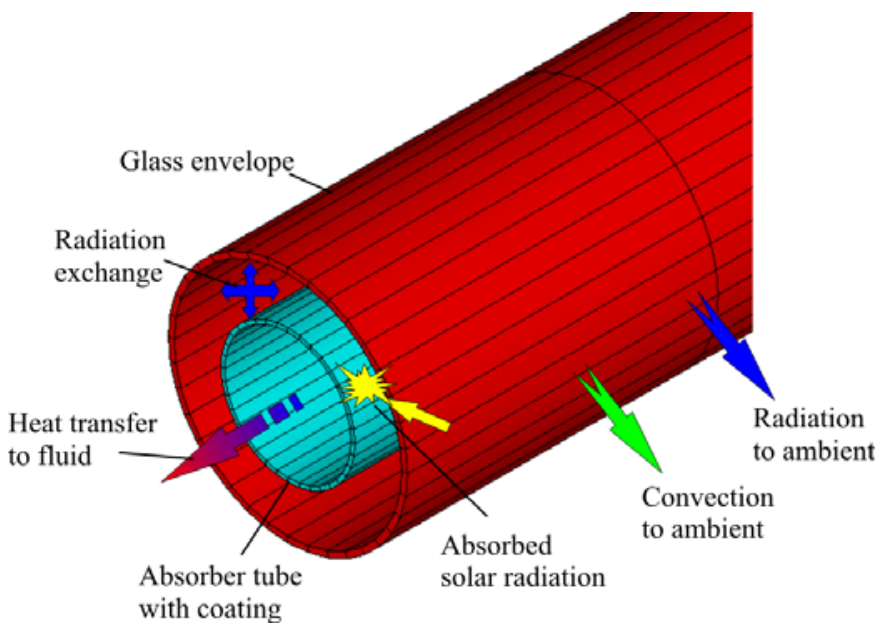

Figure 6: Schematic diagram of the FEM- Model used.

The heat transfer to the fluid was modelled using a onedimensional fluid element which is able to transport mass and heat by fluid mass flow. A constant heat transfer coefficient on the inner side of the receiver tube is considered in this particular study determining the heat transfer to the fluid. Generally, the heat transfer coefficient can be calculated or predefined at every inner surface node. Temperature dependent fluid properties as well as tube material properties (conductivity, emissivity) were considered. Diffuse gray radiation exchange between the receiver tube and the glass envelope was modelled using the radiosity method. In the same way the radiation to ambient of the glass envelope was modelled. Further, a convective heat loss was modelled using a fixed convective boundary on the outer side of the glass tube. The tube ends were estimated to be adiabatic.

The heat flow to the fluid, the convective and the radiative losses were evaluated as well as the three-dimensional temperature fields of the receiver tube (s. Figure 7) and the glass envelope and the according minimal and maximal temperatures of the components and the fluid.

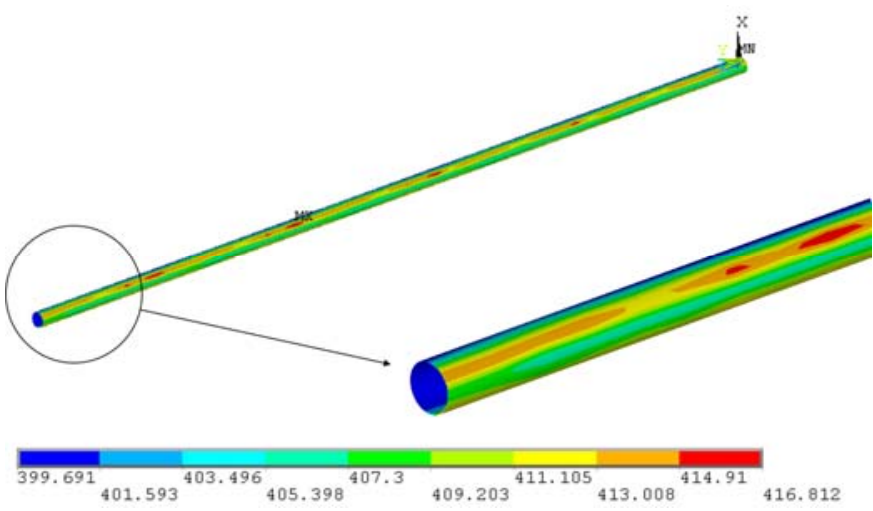

Figure 7: Temperature field receiver tube $\left[{ }^{\circ} \mathrm{C}\right]$

To determine the dependence of the grid size on the simulation results, a net study was performed. Therefore several different mesh densities of the FEM-model were analyzed and the results (heat losses) were analyzed (s. Figure 8 ). The mesh density finally used has a discretization error of less than $1 \%$.

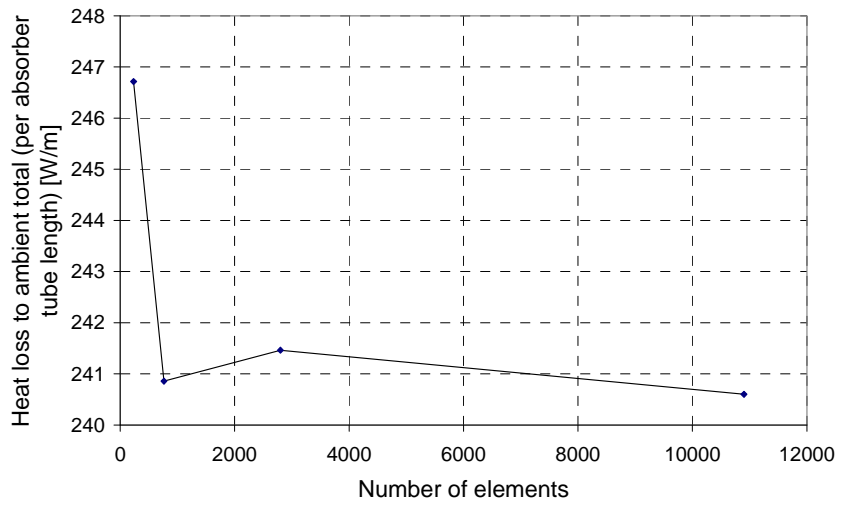

Figure 8: Result of the net study 


\subsection{Model Comparison}

The models presented differ in structure as well as in complexity. The main characteristics of the models are summarised in Table 1.

The FEM model is a three-dimensional model, whereas the analytical model is two-dimensional and the Sandia model onedimensional. Accordingly a three-dimensional heat flux profile can be used as the main input for the FEM model. Due to the simple structure of the analytical model a constant irradiation value is used for the irradiated segment and an estimated constant heat loss value is used for the un-irradiated segment. The Sandia model considers a single constant heat flux. For a more reliable comparison, a constant heat transfer coefficient between the fluid and the receiver tube is used for all models.

Table 1: Comparison of the models under investigation

\begin{tabular}{|c|c|c|c|}
\hline & Analytical & Sandia & FEM \\
\hline Dimensions & 2 & 1 & 3 \\
\hline $\begin{array}{l}\text { Glass } \\
\text { Considered }\end{array}$ & No & Yes & Yes \\
\hline \multicolumn{4}{|c|}{ Input data } \\
\hline Heat Flux & $\begin{array}{l}\text { Simple Profile } \\
\text { (Pill Box) }\end{array}$ & Constant & $\begin{array}{l}\text { Real Profile } \\
\text { (e.g. Figure 2) }\end{array}$ \\
\hline $\begin{array}{l}\text { Fluid } \\
\text { Temperature }\end{array}$ & No & Yes & Yes (inlet) \\
\hline $\begin{array}{l}\text { Heat } \\
\text { Transfer } \\
\text { Coefficient }\end{array}$ & Yes (constant) & $\begin{array}{c}\text { Yes } \\
\text { (constant) }\end{array}$ & $\begin{array}{l}\text { Yes (constant/ } \\
\text { variable) }\end{array}$ \\
\hline \multicolumn{4}{|c|}{ Output data } \\
\hline Temperature & $\begin{array}{l}\text { Distribution on } \\
\text { mean perimeter }\end{array}$ & $\begin{array}{l}\text { Constant } \\
\text { value for } \\
\text { each node }\end{array}$ & $\begin{array}{c}\text { 3-dimensional } \\
\text { temperature } \\
\text { fields }\end{array}$ \\
\hline Heat Losses & No & Yes & Yes \\
\hline \multicolumn{4}{|c|}{ Effects considered } \\
\hline $\begin{array}{l}\text { Heat } \\
\text { transfer } \\
\text { inside }\end{array}$ & Yes & Yes & Yes \\
\hline $\begin{array}{l}\text { Heat } \\
\text { conduction } \\
\text { in receiver } \\
\text { wall }\end{array}$ & Circumferential & Radial & $\begin{array}{c}\text { Axial } \\
\text { Radial } \\
\text { Circumferential }\end{array}$ \\
\hline $\begin{array}{l}\text { Radiation: } \\
\text { receiver- } \\
\text { glass }\end{array}$ & No & Yes & Yes \\
\hline $\begin{array}{l}\text { Diffusion: } \\
\text { receiver- } \\
\text { glass }\end{array}$ & No & Yes & Not Yet \\
\hline $\begin{array}{l}\text { Convection: } \\
\text { glas- } \\
\text { ambient }\end{array}$ & No & Yes & Yes \\
\hline $\begin{array}{l}\text { Radiation: } \\
\text { glas- } \\
\text { ambient }\end{array}$ & No & Yes & Yes \\
\hline Bellows & No & No & Not Yet \\
\hline
\end{tabular}

The results of the Sandia model are constant temperatures for every node considered and the heat fluxes between the nodes. The analytical model calculates the temperature distribution on the mean perimeter only and it calculates the temperature difference between the fluid and the mean perimeter directly, thus no fluid temperature is required as a model input. The FEM model calculates three-dimensional profiles of the material temperatures and the according heat fluxes. Another calculation result not used in this study is the mechanical stress in the receiver components.

The Sandia model considers all relevant heat fluxes except the circumferential and axial heat conduction in the receiver pipe and the glass envelope. In the present version, the FEM model neglects the heat losses through the bellows and the convective heat transfer between the receiver tube and the glass pipe. Due to the vacuum between the receiver tube and the glass envelope as well as the thermal insulation of the bellows, this simplification seems acceptable, especially since both effects are difficult to parameterize. Nevertheless, it is intended to extend the model accordingly in the future.

\section{SIMULATION RESULTS}

For the simulation, the geometry and the optical and thermal properties of a PTR-70 with improved coating are chosen [8, 9]. The relevant boundary conditions are summarised in Table 2.

Table 2: Main boundary conditions for simulations performed.

\begin{tabular}{|l|c|c|}
\hline Item & Value & Ref. \\
\hline Outer receiver diameter [mm] & 70 & {$[9]$} \\
\hline Wall thickness [mm] & $2^{1}$ & \\
\hline Thermal emittance [-] & $0.1 @ 400^{\circ} \mathrm{C}$ & {$[9]$} \\
\hline Solar absorptance [-] & 0.95 & {$[9]$} \\
\hline Outer diameter of glass tube [mm] & 125 & {$[9]$} \\
\hline Wall thickness of glass [mm] & 3 & {$[3]$} \\
\hline Solar absorptance of glass tube [-] & 0.02 & \\
\hline Solar transmittance of glass tube [-] & 0.96 & {$[9]$} \\
\hline Length of HCE [mm] & 4060 & {$[9]$} \\
\hline Receiver Material & 1.4541 & {$[9]$} \\
\hline
\end{tabular}

Two different irradiance conditions are impressed on the receiver tube. One condition represents the defocused heat loss case, i.e. $G_{b}=0 \mathrm{~W} / \mathrm{m}^{2}$. The other represents the operation case with an experimental $G_{b}$ of $850 \mathrm{~W} / \mathrm{m}^{2}$. This leads to the simulation matrix shown in Table 3.

In a first step, the heat losses for the HCE under investigation are calculated with the Sandia and the FEM model and compared to measured data from literature. Afterwards the according temperature profiles are calculated with the analytical and the FEM model. These calculations are used for a preliminary cross check of the different models.

\footnotetext{
${ }^{1}$ Own estimation
} 
Finally, the efficiency factor $F$ ' is determined as the ratio of the irradiated and the un-irradiated reference cases.

Table 3: Simulation matrix

\begin{tabular}{|c|c|c|}
\hline Variant number & $G_{b}\left[\mathrm{~W} / \mathrm{m}^{2}\right]$ & $\Delta T[\mathrm{~K}]$ \\
\hline 1 & 0 & 25 \\
\hline 2 & 0 & 225 \\
\hline 3 & 0 & 275 \\
\hline 4 & 0 & 325 \\
\hline 5 & 0 & 375 \\
\hline 6 & 850 & 25 \\
\hline 7 & 850 & 225 \\
\hline 8 & 850 & 275 \\
\hline 9 & 850 & 325 \\
\hline 10 & 850 & 375 \\
\hline
\end{tabular}

\subsection{Heat Losses}

The heat losses of a HCE can be calculated with the FEM model and the Sandia model for the irradiated as well as for the un-irradiated case. In a first step the heat losses for the unirradiated case are calculated and compared to measurements, known from literature [10].

Figure 9 displays the measured heat losses for a SCHOTT PTR-70 HCE and a HCE with the same dimension but an improved coating (PTR-70 New Generation), taken from [10]. Furthermore, the heat loss for the PTR-70 with the improved coating was calculated with the FEM and the Sandia model. According to Figure 9 the agreement between measured and calculated values as well as between both modelling approaches is very satisfactory. In fact, the deviation between the calculated and the measured values is less than $2 \%$ for all cases. The deviation between the two models is even less than $0.4 \%$.

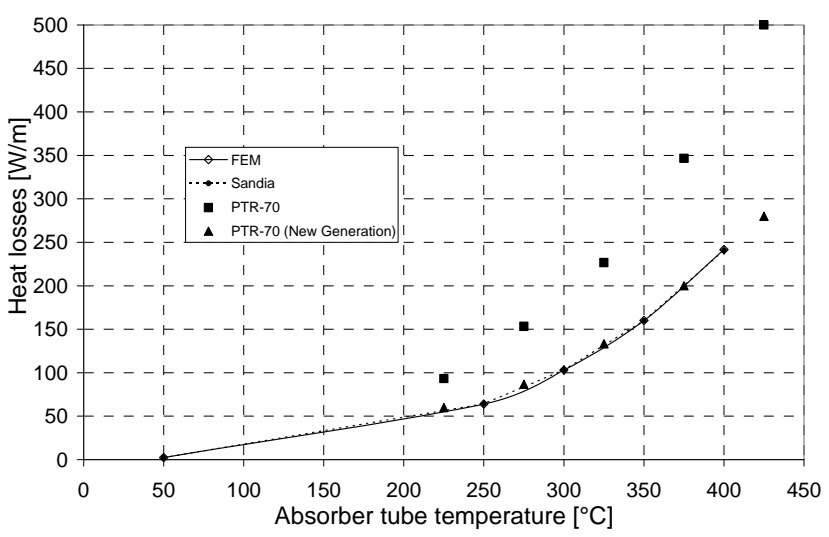

Figure 9: Measured and calculated heat losses of the unirradiated receiver tube (measurements taken from [10], $G_{b}=$ $\left.0 \mathrm{~W} / \mathrm{m}^{2}, h_{f, I}=5000 \mathrm{~W} / \mathrm{m}^{2} \mathrm{~K}, T_{a m b}=25^{\circ} \mathrm{C}\right)$.

Due to the good agreement of the comparison presented above it may serve as a preliminary validation of the models used. Thus it is justified to use the same models also for the irradiated case.
Figure 10 displays the calculated heat losses of the irradiated HCE with the optical parameters of the improved PTR-70 listed in Table 2. The results displayed show the same characteristic for both models. Nevertheless, the deviation between them is increased from less than $0.4 \%$ for the unirradiated reference case to $3 \%$ for the irradiated case. This increased deviation is mainly attributed to the use of a distinct flux profile in the FEM model, whereas the Sandia model considers a constant flux. Thus the FEM model will calculate a distinct temperature profile on the outer surface. Since the heat losses are not a linear function of the receiver temperature, the temperature peaks calculated in the FEM model will cause an increased heat loss of the HCE.

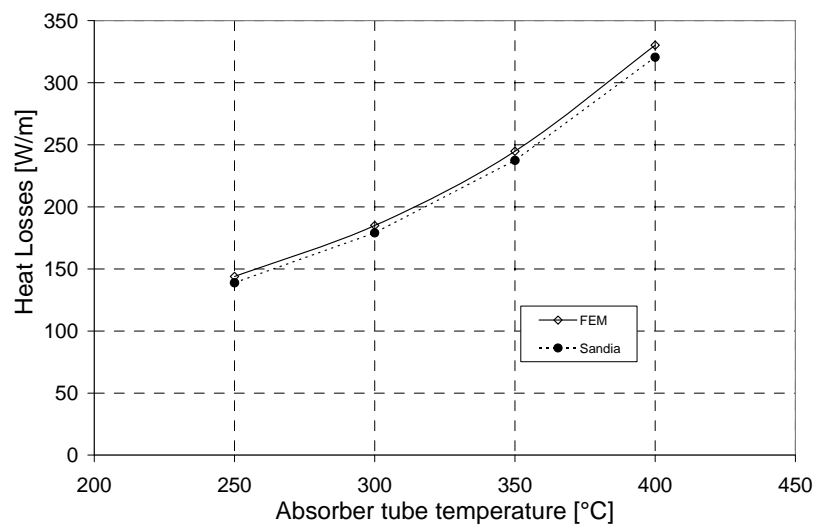

Figure 10: Calculated heat losses of the irradiated receiver tube $\left(G_{b}=850 \mathrm{~W} / \mathrm{m}^{2}, h_{f, I}=5000 \mathrm{~W} / \mathrm{m}^{2} \mathrm{~K}, T_{a m b}=25^{\circ} \mathrm{C}\right)$.

Comparing Figure 9 with Figure 10, it becomes obvious that the heat losses of the HCE are increased significantly if the $\mathrm{HCE}$ is irradiated. According to Figure 11, the increase is not constant, but decreases with increasing fluid temperature.

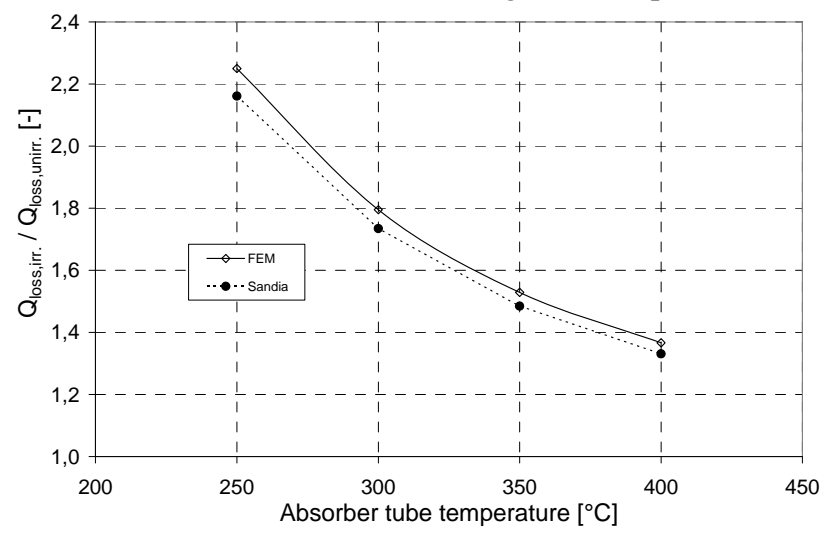

Figure 11: Heat losses of the irradiated case for the FEM and the Sandia models compared to the un-irradiated case.

In the operation range of state-of-the-art parabolic trough plants $\left(T \approx 300-400^{\circ} \mathrm{C}\right)$ the specific heat losses for this particular case are increased by 40 to $80 \%$. One reason for this increase is the increased outer receiver temperature in the irradiated case and the accordingly increased heat losses. 
Another reason is the fact that a specific fraction of the concentrated DNI is already absorbed by the glass envelope. This increases the temperature of the glass envelope and thus the heat losses to the ambient too. Since this effect is not a function of the receiver temperature but nearly constant, this effect is more dominant at lower receiver temperatures and hence $Q_{\text {loss,irr }} / Q_{\text {loss, unirr }}$ is larger at lower receiver temperatures.

\subsection{Temperature Profile}

The temperature profile in the receiver tube is an important result of the different receiver models. It determines the maximum temperature at the outer surface and thus the maximum operation temperature of the selective coating. It also determines the temperature distribution in the receiver and thus the thermal load and the according mechanical stress in the receiver tubes.

The three-dimensional FEM model calculates the receiver temperature at every node of the model. Accordingly, the calculated temperature profile will reflect the influence of the considered flux profile. The Sandia model will calculate one constant temperature at the inner surface of the receiver tube and one constant temperature at the outer surface. Finally, the analytical model calculates the temperature distribution on the mean perimeter of the receiver tube based on a simplified flux distribution (pill box) at the outer surface. The receiver temperature calculated with the different programs is displayed in Figure 12 for one specific case with a fluid temperature of $350^{\circ} \mathrm{C}$.

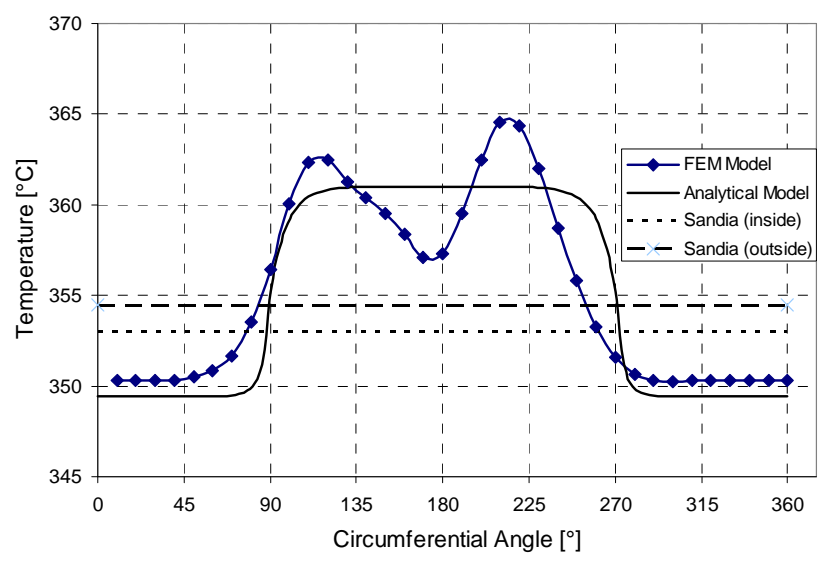

Figure 12: Temperature profile calculated with the FEM-model and temperature distribution on the mean perimeter, calculated with the analytical model. $\left(G_{b}=850 \mathrm{~W} / \mathrm{m}^{2}, T=350^{\circ} \mathrm{C}, h_{f, I}=\right.$ $\left.5000 \mathrm{~W} / \mathrm{m}^{2} \mathrm{~K}, T_{a m b}=25^{\circ} \mathrm{C}\right)$

For the FEM-model the temperature profile at the inner and outer surface is displayed. For the analytical model the temperature profile on the mean perimeter is displayed and for the Sandia model the calculated temperatures at the inner and outer surfaces are displayed. According to Figure 12, the temperature difference between the inner and outer surface is less than $1.5 \mathrm{~K}$ (result of Sandia and FEM-model). This is mainly due to the small receiver wall thickness of only $2 \mathrm{~mm}$. But due to the distinct flux profile considered in the FEMmodel hot spots occur in the receiver tube causing a maximum receiver temperature $16 \mathrm{~K}$ higher than the operation temperature of the HTF.

According to the comparison of the results, the Sandia model is not suited for the determination of the maximum receiver temperature but for the temperature gradient over the receiver wall. The analytical model gives no information about the temperature gradient, but gives a first hint on the maximum operation temperature on the mean perimeter of the receiver tube. With a simple extension it determines the maximum temperature on the outer surface too. Since the model considers only a simple flux profile, the distribution of the temperature is not as detailed as the distribution calculated with the FEMmodel.

The FEM-model used is able to calculate the threedimensional temperature filed in the receiver tube, considering a realistic flux profile on the outer surface. Accordingly, this model is suited to calculate the maximum operation temperature of the receiver tube and thus of the selective coating. Furthermore, it can be used to determine the thermal load of the receiver tube.

\subsection{Efficiency Factor}

The most interesting question regarding the consideration of the un-irradiated heat losses for yield calculations instead of the irradiated heat losses is what is the effect on the useful energy of the HCE is. As described in section 2, in theory this effect is described by the efficiency Factor $F^{\prime}$. Figure 13 displays the efficiency factor calculated with equation 2 and derived from the heat losses calculated with the FEM and the Sandia models. In the latter cases the efficiency factor is calculated according to

$$
F^{\prime}=\frac{\dot{Q}_{a b s}-l \cdot \dot{q}_{\text {loss }, \text { irr }}}{\dot{Q}_{a b s}-l \cdot \dot{q}_{\text {loss }, \text { unirr }}}
$$

Thus the efficiency factor is defined as the ratio of the useful energy of the irradiated case to the useful energy of the un-irradiated case. Since this is not exactly the same definition as the definition of the efficiency factor given in section 2 , it is obvious that the results of the theoretical and the model calculations will have a systematic deviation. The main difference is, that the effect of irradiation is not considered in the standard definition of $F^{\prime}$. Nevertheless, two main conclusions can be derived from Figure 13: the efficiency factor derived from equation 3 is more sensitive to the fluid temperature than the theoretical value and the theoretical value is significantly higher than the value according to equation 3 .

The temperature dependency of the model results is more distinct, since the models consider the absorption of the concentrated DNI by the glass envelope. The absolute deviation in the results is not only caused by the differing definitions, but also by the consideration of the absorption of the glass 
envelope and the distinct flux profile in case of the FEM model.

For the particular case presented in Figure 13, the useful energy of a HCE is reduced by approx. $2.5 \%$ if the HCE is irradiated. Thus a systematic error of approx. $2.5 \%$ exists when calculating the energy yield of an receiver tube using heat losses measured in lab tests instead of considering the heat loss of an irradiated HCE. Accordingly in most cases the energy yield of a parabolic trough collector field is overestimated by $2.5 \%$, if only these simple heat loss correlations are used.

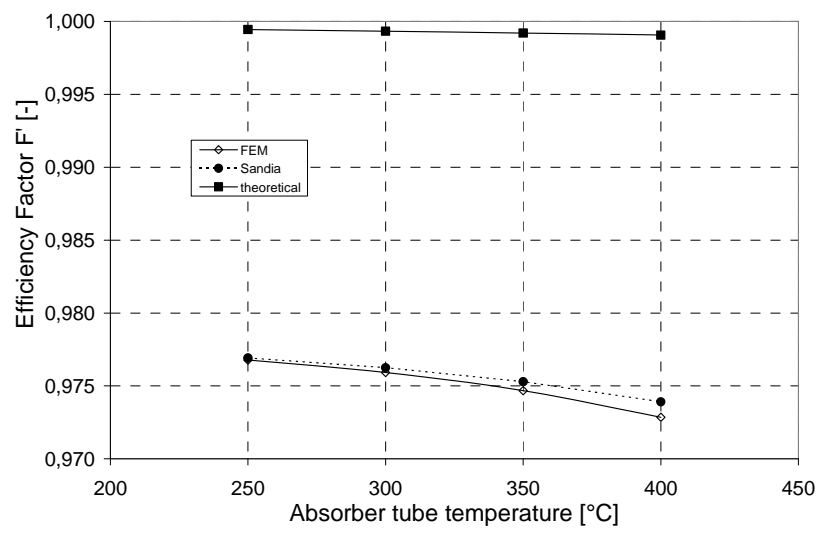

Figure 13: 'Efficiency Factor' $F$ ' calculated with the FEM and the Sandia models compared to the theoretical calculation.

\section{SUMMARY AND CONCLUSIONS}

Three different receiver models are presented and compared, a three-dimensional FEM model, the empirical onedimensional model of Sandia and a two-dimensional analytical model.

Regarding the calculation of the temperature profile in the receiver tubes, it was shown that the distinct flux profile used in the FEM-model has a significant influence on the determination of the maximum receiver temperature. In the particular case investigated in this paper, the maximum receiver temperature is approx. $16 \mathrm{~K}$ higher than the fluid temperature.

In this paper it was shown that the Sandia model is a good tool for the determination of the thermal parameters of the receiver tubes but is not suited for a more detailed analysis of the receiver temperature. The developed FEM-model is a helpful tool for the investigation of the heat losses as well as for the detailed analysis of the temperature field.
It was shown that the heat loss of a receiver tube calculated with the FEM model and the Sandia model are in good agreement with measured data. For a particular case, it was shown that the heat losses of the un-irradiated HCE are increased by 40 to $80 \%$, if it is irradiated. Determining the energy yield of a HCE using heat losses of the un-irradiated case will cause an overestimation of approx. $2.5 \%$. This is more than estimated by the efficiency factor $F^{\prime}$. One reason for this deviation might by the fraction of the concentrated irradiation absorbed by the glass envelope of the receiver tube. The absorbed irradiation increases the temperature of the glass envelope considerably and thus the convective heat losses to the ambient. To verify this assumption, a more detailed investigation is currently performed.

\section{REFERENCES}

1. Dudley, V.E., et al., Test Results - SEGS LS-2 Solar Collector. 1994, SANDIA: Albuquerque. p. 32.

2. Eck, M. and W.-D. Steinmann, Modelling and Design of Direct Solar Steam Generating Collector Fields Journal of Solar Energy Engineering, 2005. 127: p. 371.

3. Eck, M., et al., Development of Receivers for the DSG Process, in SolarPACES 2006. 2006: Seville. p. 7.

4. Lüpfert, E., et al., Experimental Analysis of Overall Thermal Properties of Parabolic Trough Receivers. Journal of Solar Energy Engineering, 2008. 130(2): p. 021007.

5. Duffie, J.A. and W.A. Beckman, Solar Engineering Thermal Processes. 2nd ed. 1991, New York, Chichester, Brisbane, Toronto, Singapore: John Wiley \& Sons.

6. Lüpfert, E., et al., Determination of Temperature Distribution on Parabolic Trough Receivers, in SolarPACES 2006. 2006: Seville. p. 6.

7. Forristall, R., Heat Transfer Analysis and Modeling of a Parabolic Trough Solar Receiver Implemented in Engineering Equation Solver. 2003, National Renewable Energy Laboratory: Golden, Colorado.

8. Kuckelkorn, T., et al. Advances in Receiver Technology for Parabolic Trough Collectors - A Step Forward Towards Higher Efficiency and Longer Lifetime. in SolarPACES. 2009. Berlin: SolarPACES.

9. SCHOTT, SCHOTT PTR-70 Receiver - The Next Generation, S. Solar, Editor. 2009: Mitterteich. p. 4.

10. Benz, N., Receiver Tubes, in SolarPACES. 2009: Berlin. 